\title{
Финтех: сущность и модели реализации
}

и.Д. котляров, кандидат экономических наук, НИУ «Высшая школа экономики», Санкт-Петербург

В статье рассмотрена сущность финансовых технологий, предложена историческая периодизация этапов их эволюции с подробным описанием содержания каждого из этапов, перечислены факторы, обусловившие возникновение и быстрое распространение этого феномена. Сформирован перечень основных моделей сосуществования традиционных и инновационных подходов к предоставлению финансовых услуг и описано содержание каждой из моделей. Показано, что наибольшим конкурентным потенциалом будут обладать те финансовые учреждения, которые в той или иной форме сочетают традиционные и инновационные модели финансовой деятельности.

Ключевые слова: финансовые технологии, финтех, банки, финансовые услуги

JEL: G20, G29

В настоящее время самым бурно растущим сегментом рынка финансовых услуг являются так называемые финансовые технологии, которые можно в первом приближении описать как инновационные (прежде всего - с технологической точки зрения, однако зачастую применение инновационных технологий сопровождается организационными и продуктовыми инновациями) модели взаимодействия участников этого рынка. Эти технологии активно внедряются как традиционными игроками финансового рынка (банками, инвестиционными, страховыми и иными компаниями), так и специально созданными для их использования финансово-технологическими структурами [Кудрявцева, 2017; Кузнецов, 2017; Осадчий, 2017; Усоскин и др., 2017]. Кроме того, на этот рынок активно выходят организации из других секторов экономики. Наглядный пример такой тенденции - запуск платежных систем Samsung Pay и Google Pay, созданных корейским производителем электроники Samsung и американской интернет-компанией Google, а в России - запуск сервиса денежных переводов социальными сетями «Вконтакте»и «Одноклассники» и почтовой службой Mail.ru.

Несмотря на бурный рост финансово-технологического сектора, на сегодняшний день существует крайне мало научных 
публикаций, посвященных специфике его функционирования как самостоятельной подотрасли и одной из магистральных тенденций развития рынка финансовых услуг. В качестве примера такой фундаментальной работы можно привести, пожалуй, лишь коллективную монографию [Banking.., 2016]. Этот пробел не могут восполнить ни многочисленные публикации, посвященные отдельным разновидностям финансовых технологий блокчейна и криптовалют [Демьянова, 2017; Корнивская, 2017; Михайлов, 2018; Филин, Чайковская, 2018; Нурмухаметов и др., 2017; Обухова, 2018; Пестунов, 2018; Трофимов, 2018; Sigova, Khon, 2017 и др.], поскольку они не позволяют оценить особенности функционирования и перспективы развития сектора в целом, ни аналитические обзоры рынка финтеха [НМ Treasury.., 2015; KPMG, 2016], которые направлены на исследование текущего состояния отрасли, но не на его теоретическое осмысление.

Ниже мы попытаемся показать сущность и причины возникновения финансовых технологий (финтеха), обратив особое внимание на возможные модели сосуществования традиционного финансового сектора и финтеха. Будучи ограничены рамками статьи, мы рассматриваем в качестве представителей традиционного финансового сектора преимущественно банки, хотя основные выдвигаемые нами тезисы справедливы и для других традиционных финансовых структур.

\section{Сущность финансовых технологий}

Финансовые технологии можно определить как сочетание финансовых услуг (и, шире, финансовой деятельности) и информационных технологий. Финтех воспринимается как инновационное явление, но его инновационный характер на самом деле очень зыбок и эфемерен - то, что вчера казалось инновационным, в настоящее время перестает таким быть и воспринимается как нормальная, стандартная часть финансовых услуг (как, например, дистанционное банковское обслуживание). Вероятно, лучше всего отражать сущность финтеха будет его трактовка как сочетания инновационных финансовых продуктов с инновационными финансовыми технологиями (хотя на самом деле в финтех включаются многие продукты и услуги, выходящие 
за пределы этого определения $\left.{ }^{1}\right)$. Фактически в этом случае речь идет о самоподдерживающемся процессе: инновационные технологии порождают инновационные продукты (поскольку делают возможным их предоставление), а создание инновационных финансовых продуктов влечет за собой появление новых технологий (необходимых для их более эффективного предоставления). При этом сами инновационные продукты могут представлять собой современную, более технологичную версию продуктов или видов деятельности, которые существовали с давних пор.

Хорошим примером может быть краудфинансирование:

- само по себе привлечение большого числа взносов для реализации крупных проектов - как коммерческих, так и некоммерческих - известно давно (строительство многих храмов и памятников финансировалось по такой модели; «подписные» книжные издания, заказы на которые формировались с частичной предоплатой), однако именно Интернет позволил сделать механизм сбора средств массовым и удобным для всех и создал условия для возникновения прозрачных и общепринятых организационных моделей краудфандинга в его современном виде [Панова, 2018; Филимонова и др., 2017];

- в то же время возникновение краудфинансирования привело к появлению множества специализированных интернет-платформ, создающих условия для эффективного сбора пожертвований, и институционализации этого процесса.

Развитие и распространение финтеха представляет собой частный случай перехода к цифровой экономике - речь идет о цифровизации финансовой деятельности [Савина, 2018; Устюжанина и др., 2017].

\section{История финтеха}

Внедрение информационных технологий в финансовой сфере имеет давнюю историю, поскольку сама информация (о наличии денежных средств, их движении, форме и т.д.) играет важную роль для эффективной организации финансовой деятельности,

\footnotetext{
${ }^{1}$ Вероятно, в этой связи целесообразно разграничивать финтех в узком смысле (основанный на сочетании инновационных технологий и инновационных продуктов) и широком (предполагающий использование либо инновационных технологий, либо инновационных продуктов), однако столь глубокий анализ сущности финтеха уводит нас далеко за пределы целей статьи.
} 
и поиск надежных способов хранения, передачи и обеспечения доступа к этой информации издавна волновал финансистов. Вряд ли будет ошибкой утверждать, что прокладка телеграфных кабелей в XIX в., соединившая между собой страны Европы, Европу с Великобританией и позже с США, и тем самым многократно ускорившая информационный обмен, воспринималась в то время как своего рода финтех.

В том же XIX в. была создана платежная система Western Union - хороший пример выхода тогдашней высокотехнологичной компании (оператора телеграфных линий) на рынок финансовых услуг. Сегодня история повторяется: выход облачного оператора электронной почты Mail.ru на рынок денежных переводов, по сути, воспроизводит модель Western Union на новом этапе развития технологий.

Тем не менее периодизацию финтеха следует строить с середины XX в. - начиная со времени распространения компьютеров, потому что именно компьютеры ознаменовали переворот в технологиях обработки информации. С тех пор до наших дней отчетливо выделяются три этапа развития финтеха.

Первый-условно этап зарождения, столь же условно можно отнести к периоду с 1940-х до середины 1990-х гг. В это время финансово-информационные технологии оставались замкнутыми внутри банковского и корпоративного секторов и использовались главным образом для предоставления традиционных банковских услуг.

Это было обусловлено высокой стоимостью компьютеров (особенно предназначенных для обработки больших массивов информации), низкой мощностью и недостаточным уровнем распространения персональных компьютеров, отсутствием массовых телекоммуникационных сетей, которые бы связывали потребителей с провайдерами финансовых услуг и позволяли получать эти услуги удаленно в автоматическом режиме. Телекоммуникационные сети в то время либо не предполагали автоматизацию (телефонный доступ к банковским услугам осуществлялся через оператора), либо были немассовыми (корпоративными, локальными), такими, как сети банкоматов и платежных терминалов. Эти устройства находятся под полным контролем финансовых структур (банков и платежных систем) и являются устройствами коллективного, а не индивидуального пользования. 
Ближе к середине 1990-х некоторые финансовые услуги стало возможно получать удаленно (по телефону) или в автоматическом режиме (через банкомат), но их спектр был достаточно узким. В любом случае доступ клиентов к использованию информационных технологий был возможен только через банк, который предоставлял определенные ресурсы для потребителей (например, банкоматы). Собственных ресурсов для использования информационных технологий у клиентов не было, что и означает, что эти технологии были замкнуты внутри банковского сектора. В этот же период возникает глобальная межбанковская платежная система SWIFT, происходит массовый переход к использованию безналичных платежей, в том числе среди частных лиц - на основе пластиковых карт. Тогда же появились первые национальные информационные сети и домашние терминалы для доступа к ним (французская сеть Minitel), которые позволяли получить в том числе финансовые услуги. Однако недостаточное удобство использования в сочетании со сравнительно высокой стоимостью получения услуг (доступ к серверам провайдеров услуг зачастую был платным) ограничивали их применение.

Bторой этап (со второй половины 1990-х гг. до рубежа 2010-х гг.) - ранний. Его характеризует распространение и массовое использование Интернета, появление и быстрый рост электронной коммерции, переход к дистанционному предоставлению традиционных финансовых услуг (онлайн-банкинг), возникновение специфических электронных платежных инструментов (электронные деньги, электронные чеки) и создание массовых электронных платежных систем (Paypal, Kiwi и др.). Электронные платежные инструменты направлены в первую очередь на обеспечение взаимодействия между традиционными потребителями и игроками рынка электронной коммерции. Они стали первыми провозвестниками массового финтеха, альтернативой традиционным финансовым институтам (мы лишь упомянем их, не останавливаясь подробно на анализе деятельности). Информационные технологии вышли за пределы корпоративного сектора и стали общедоступными. Функционал банкоматов расширяется, они позволяют выполнять широкий спектр операций, становясь финансовыми сервисными терминалами. Интернет-взаимодействие пока служит дополнением к реальному взаимодействию между людьми и организациями, а не замещает его. 
Начало третьего, зрелого этапа (в котором мы находимся в настоящее время) предлагается датировать началом 2010-х гг. В ходе этого этапа использование Интернета стало массовым и постоянным благодаря распространению устройств, дающих доступ к нему независимо от местонахождения владельца. Сформировалось виртуальное информационное пространство, в котором человек стал проводить значительную часть времени и в которое перетекла значительная (в ряде случаев - бо́льшая) часть его социальных и профессиональных взаимодействий. Произошла трансформация потребительских привычек - получение услуг, в том числе и финансовых, в виртуальном пространстве стало общепринятым. Это не означает, разумеется, что все услуги стали потребляться исключительно по Интернету - однако использование Интернета для потребления услуг стало массовым, а потребители в значительной степени избавились от недоверия к такого рода взаимодействию. По данным за 2011 г., в странах Западной Европы и Америки услугами интернет-банкинга пользовались более 50\% взрослого населения; в России более 90\% крупных банков предоставляли клиентам возможности онлайн-банкинга (среди мелких банков - 15\%) [Обухов, Осиповская, 2012].

Возникли принципиально новые виды финансовых активов (криптовалюты) и финансово-инвестиционных продуктов (ICO - Initial Coin Offering), а также связанной с ними предпринимательской деятельности (майнинг криптовалют). Трансформируются технологии доступа к финансовым услугам - человек сам становится носителем идентифицирующей его информации, не нуждаясь в пластиковых картах и документах, удостоверяющих его личность (биометрическая аутентификация). Появились виртуальные банки (Tinkoff).

Является ли зрелый этап эволюции финтеха окончательной стадией его развития? Дать ответ на этот вопрос очень сложно. Безусловно, информационные и организационные технологии предоставления финансовых услуг (и, шире, функционирования участников финансового рынка) будут развиваться и дальше. Но при этом мы полагаем, что будет происходить постепенное сближение традиционных и инновационных финансовых институтов, в силу чего те инструменты и модели, которые сейчас воспринимаются как присущие исключительно финтеху, станут 
неотъемлемым элементом финансовой системы в целом и войдут в практику традиционных институтов. Это будет означать, что финтех перестанет восприниматься как самостоятельный феномен, противопоставленный традиционным моделям организации финансовой деятельности, и тогда зрелый этап будет последним в качестве независимого существования финтеха, на котором финтех (вместе с финансовой системой) перейдет на этап развития, который мы бы предложили назвать интегральным.

Представленная выше хронология этапов носит в известной степени условный характер. В разных странах датировки этих периодов будут различаться, и, более того, разные регионы одной и той же страны могут находиться на разных этапах эволюции (в частности, мегаполисы более развиты по сравнению с провинциальными городами).

\section{Факторы эволюции финтеха}

Факторами, обусловившими возникновение, развитие и широкое распространение финансовых технологий, на наш взгляд, являются:

- качественный и количественный рост информациионных технологий. Качественный рост выражается в том, что их потенциал вырос до такой степени, что сделал возможным быстрое и безопасное выполнение сложнейших финансовых транзакций. Потребители могут совершать операции по своим счетам круглосуточно, из любой точки и в режиме реального времени. Количественный рост заключается в практически всеобъемлющей доступности технологий, охвате ими большей части населения нашей планеты и возможности их использования в любой точке земного шара. Доступность обеспечивается как с финансовой точки зрения (стоимость соответствующих устройств и сервисов вполне приемлема), так и с технологической (использование технологий не требует специальных знаний, а сами устройства компактны и просты в применении);

- трансформация потребительских привычек. Все большее число потребителей считают для себя нормальным и приемлемым приобретать широкий спектр товаров и услуг, в том числе и финансовых, в сети Интернет;

- потребность финансовых и нефинансовых организаций в повышении эффективности своей деятельности. Финансовые 
организации стремятся снизить свои издержки за счет внедрения дистанционного обслуживания и автоматизации, повысить качество предоставления услуг и адаптировать модель оказания услуг к изменившимся запросам потребителей. Нефинансовые организации за счет финтеха надеются обеспечить более высокий уровень монетизации своей целевой аудитории (и своих стейкхолдеров, например, посредством краудфандинга [Филимонова и др., 2017]), а также ее лояльность за счет предоставления им все большего количества сервисов. Примером могут быть финансовые сервисы «Вконтакте» и Mail.ru - теперь пользователям для совершения финансовых операций нет необходимости прибегать к услугам сторонних организаций, и, как следствие, они могут проводить больше времени на сайтах этих компаний.

\section{Сосуществование традиционных финансовых услуг и финтеха}

Важной проблемой в настоящее время является поиск моделей сосуществования традиционных и инновационных финансовых услуг. При этом необходимо понимать, что часть инновационных элементов финтеха со временем переходит в разряд стандартных процедур (например, бесконтактные платежи), а часть может быть совсем незаметна для потребителей, поскольку затрагивает только технологию производства финансового продукта, но не его форму (например, внедрение технологии блокчейна платежными системами).

На наш взгляд, речь идет о существовании некоего континуума переходных форм между двумя крайними точками - чисто консервативной и циифровой моделями оказания финансовых услуг. Первая из них целиком опирается на традиционные услуги и осваивает только те элементы финтеха, которые уже имеют давнюю историю применения, последняя использует только инновационные элементы. Существование таких переходных форм объясняется как стремлением финансовых институтов сочетать преимущества традиционной и цифровой моделей предоставления финансовых услуг, так и пока имеющимися для отдельных финансовых продуктов ограничениями по переводу их в полностью цифровой формат.

Несмотря на популярность финтеха и его высокую эффективность, у консервативной модели есть своя сфера применения. 
Использование этой модели позволяет лучше защитить личную информацию клиентов, что может быть важно для определенной категории потребителей. Кроме того, она не устраняет личное, человеческое общение (что имеет большое значение в сегменте private banking). Наконец, для отдельных финансовых институтов внедрение финтеха не имеет смысла, поскольку не принесет значимого экономического эффекта.

Финансовые институты, использующие такую модель, внедряют только те элементы финтеха, которые уже прошли проверку временем и не угрожают безопасности и комфорту пользователей, и при этом фактически стали стандартом предоставления финансовых услуг (иными словами, отсутствие соответствующих сервисов будет воспринято потребителями как более низкое качество обслуживания). Примером такого банка может быть Российский национальный коммерческий банк (РНКБ), являющийся системообразующим для Республики Крым и г. Севастополя, который предлагает услуги онлайн-банкинга, но при этом (по крайней мере, пока) не занимается иными финансовыми инновациями. Этот консерватизм подходов может объясняться спецификой региона, в котором банк ведет свою деятельность (и, в частности, узостью его клиентской базы и ограниченностью ресурсов), спецификой структуры собственности и/или особенностями условий ведения бизнеса (банк находится под максимально жесткими международными санкциями).

При этом, разумеется, существуют банки, которые вынуждены использовать данную модель из-за отсутствия технологических компетенций и финансовых ресурсов для внедрения финтеха. Кроме того, отдельные банки просто могли пропустить момент для внедрения финтеха, и ликвидация отставания стала невозможной или затруднительной. Для них это не целенаправленная политика, а вынужденное поведение, и такие банки, вероятнее всего, будут со временем вытесняться с рынка.

Первую из переходных моделей мы предлагаем называть дополненной консервативной. Ее отличает традиционность с точки зрения состава предлагаемых продуктов и модели взаимодействия со стейкхолдерами, но при этом использование тех инноваций, которые позволяют снизить издержки и повысить качество оказываемых услуг (а также обеспечить соответствие модели оказания этих услуг представлениям целевой аудитории). 
Примером реализации такой модели на российском рынке может быть Сбербанк, который, специализируясь на традиционных банковских продуктах, активно предоставляет их в режиме онлайн и проводит политику замещения живого труда банковских сотрудников инструментами автоматизации и самообслуживания. За счет этого потребитель может выбрать наиболее удобный для него в данный момент канал получения услуги (или комбинировать эти каналы). В сфере розничной торговли сходная модель реализуется в омниканальной ${ }^{2}$ организации продаж, когда потребитель может, например, выбрать товар в Интернете, а получить его - в традиционном магазине.

В рамках комбинированной модели первого типа финансовый институт может применять как традиционные, так и инновационные элементы. Но они не формируют единый канал создания ценности для клиентов, а существуют параллельно - в составе разных продуктов, а иногда - в виде разных брендов или даже юридических лиц, хотя с технологической и операционной точек зрения могут быть достаточно глубоко интегрированы (например, «традиционный» банк создает инфраструктуру для «надстроенной» над ним финтех-организации, которая фактически выступает в качестве виртуального финансового оператора). Такая модель позволяет использовать преимущества нового бизнес-подхода, не разрушая при этом традиционную схему функционирования финансового института. Это дает возможность организации охватить целевые аудитории с разными запросами и ориентированными на разные типы предоставления финансовых услуг, не отпугивая консервативных пользователей избыточной инновационностью и не смущая инновационно ориентированных потребителей чрезмерным консерватизмом. Примером такой модели служит краудлендинговый проект «Альфа-поток», дополняющий деятельность традиционного Альфа-банка. Проблема, однако, заключается в том, что между параллельными каналами создания ценности на определенном этапе может возникнуть конкуренция (например, при привыкании потребителей к фи-

${ }^{2}$ Омниканальность - маркетинговый термин, обозначающий интеграцию разрозненных и разнородных каналов взаимодействия с клиентом в единую систему, обеспечивающую непрерывную коммуникацию с потребителем. 
нансовым инновациям они начнут постепенно отказываться от потребления традиционных видов финансовых услуг).

Интересно отметить, что финансовые институты могут сочетать в своей деятельности дополненную консервативную модель и комбинированную. При таком сочетании внедрение финтеха в деятельность финансового института идет по двум направлениям:

- в самой организации внедряется дополненная консервативная модель, которая позволяет повысить качество взаимодействия с потребителями традиционных финансовых услуг, а также надежность функционирования внутренних бизнес-процессов (например, путем внедрения системы документооборота, основанной на блокчейне и т.д.);

- вокруг финансового института формируется облако финтехпроектов (экосистема), которые дополняют услуги традиционного банка.

Строго говоря, именно такое сочетание и реализуется в Сбербанке и Альфа-банке.

Это означает, что различные варианты комбинирования традиционных и инновационных моделей предоставления финансовых услуг не являются жестко противопоставленными - скорее, они дополняют друг друга.

Комбинированная модель второго типа построена на принципиально иной основе - при ее использовании клиенты (и стейкхолдеры) могут выбрать оптимальный для себя канал получения ценности в рамках одного финансового института (а также комбинировать эти каналы в зависимости от своих потребностей). Фактически это новый универсальный финансовый институт, построенный на инновационной технологической, организационной и продуктовой базе в сочетании с традиционными подходами. В таком финансовом институте может быть реализован принцип «одного окна», через которое можно получить доступ к любым типам финансовых услуг по выбору клиента (например, не только потребительский кредит, но и воспользоваться краудлендингом). Пока реальных примеров такой бизнес-модели в финансово-банковской сфере найти не удалось, тем не менее пространство для ее внедрения существует. Не исключено, что она будет реализована разного рода агрегаторами. 
Финансовые институты, работающие по дополненной инновационной модели, ориентируются в своей деятельности на преимущественное использование финтеха, однако наряду с ним применяют традиционные модели и инструменты предоставления финансовых услуг для того, чтобы повысить качество и комфорт своих сервисов для целевой аудитории (а также поддерживают необходимую для этого традиционную финансовую инфраструктуру). Для финтех-операторов в строгом смысле слова, ведущих свою деятельность исключительно в виртуальном пространстве, остро стоит проблема «последней мили», т.е. связи между виртуальным и реальным мирами (например, проблема снятия наличных денег со счета или внесения их на счет, получения наличных денег после проведения ICO и т.д.). Финансовые операторы, использующие дополненную инновационную модель, создают собственную инфраструктуру для решения проблемы «последней мили». В частности, к дополненной инновационной модели в настоящее время переходит банк Tinkoff, поначалу позиционировавшийся как чисто виртуальный банк, но теперь создающий собственную сеть банкоматов. Другой пример - платежная система Qiwi, использующая сеть терминалов самообслуживания. Сама система Qiwi является финтехкомпанией, и на момент внедрения ее терминалы представляли собой финансово-технологическую инновацию, но тем не менее сеть этих терминалов как материальная инфраструктура мешает компании совсем уйти в цифровое пространство.

Использование чисто инновационной модели означает, что финансовый институт отказывается от применения традиционных моделей и инструментов предоставления финансовых услуг и целиком сосредоточивается на финтехе. Примером такого подхода может быть все тот же банк Tinkoff - до выстраивания собственной банкоматной сети. В небанковской сфере можно указать на знаменитую африканскую платежную систему M-PESA. Решение проблемы «последней мили» при использовании чисто инновационной модели достигается за счет партнерства с традиционными финансовыми организациями, обладающими собственной инфраструктурой. Примером аналогичного подхода на других рынках могут быть интернет-магазины, которые в случае отсутствия собственной службы доставки прибегают к логистическому аутсорсингу. 
Возможно, в будущем, когда с развитием информационных технологий сфера применения наличных денег будет сокращена до минимума, а сами наличные средства постепенно уступят место электронным, потребность в «последней миле» отпадет, и инновационная модель будет замещена чистой изифровой, основанной исключительно на информационном взаимодействии между провайдером и потребителем финансовых услуг и не предполагающей использования материальной инфраструктуры. В сфере электронной торговли по такой чисто цифровой модели работает AppStore, торгующий информационными благами.

Вероятно, не будет большой ошибкой предположить, что основную долю рынка в любой период времени занимают операторы, прибегающие к сочетанию традиционных и инновационных элементов в той или иной пропорции. Традиционные финансовые институты постепенно дрейфуют к комбинированной модели первого и второго рода (через поглощение финтехкомпаний и создание собственных финтех-подразделений), тогда как «чистые» финтех-операторы смещаются в сторону дополненной инновационной модели путем обзаведения элементами традиционной финансовой инфраструктуры (как показывает пример банка Tinkoff). Логика такого развития предельно проста: организации стремятся получить максимум от сочетания положительных сторон инновационной и традиционной моделей, при этом нивелировав недостатки каждой из них.

Интересно отметить, что если первое направление миграции (от традиционной модели к инновационной) вызывает большой интерес у специалистов и изучается как модель трансформации традиционных финансовых институтов в условиях финтех-революции, то второе (от инновационной модели к традиционной) пока остается практически неисследованным. Это может указывать на однобокость восприятия исследователями процессов конвергенции традиционных и инновационных моделей ведения бизнеса в финансовой отрасли.

Между тем ранее похожие процессы происходили в сфере электронной торговли - инновационные интернет-магазины (наподобие Amazon и Ozon) также обзаводились традиционной торговой инфраструктурой в целях повышения эффективности своей деятельности, и по этой причине на данную тенденцию нужно обратить особое внимание. Фактически это означает, что 
специалистам в сфере управления финансовыми институтами нужно разрабатывать не только стратегии адаптации финансовых учреждений к условиям финтех-революции, но и стратегии освоения финтех-компаниями традиционных моделей ведения финансовой деятельности.

\section{Заключение}

Подводя итог, можно утверждать следующее:

- финтех, будучи основан на инновационных (с технологической, организационной и продуктовой точек зрения) моделях предоставления финансовых услуг, представляет, по сути, проявление процесса информатизации финансового сектора, и, шире, хозяйственной деятельности в целом;

- поскольку финтех на современном этапе связан с выходом нефинансовых компаний на рынок финансовых услуг, его можно трактовать как одно из направлений финансиализации ${ }^{3}$ экономики;

- факторами, обусловившими возникновение и быстрое распространение финтеха, являются качественный и количественный рост информационных технологий, потребность финансовых и нефинансовых компаний в повышении эффективности своей деятельности, а также трансформация потребительских привычек;

- можно предполагать, что доминировать на рынке финансовых услуг будут компании, сочетающие в той или иной форме традиционные и инновационные модели и инструменты предоставления финансовых услуг. Финтех-операторы будут мигрировать в сторону внедрения в свою деятельность отдельных традиционных технологий, тогда как традиционные финансовые институты будут постепенно применять элементы финтеха.

\section{Литература}

Демьянова Е.А. Критерии оценки рисков развития компаний в условиях внедрения финансовых технологий // Финансы: теория и практика. 2017. Т. 21. № 4. С. $182-190$.

Корнивская В.О. Биткоин и блокчейн сквозь призму глубинных условий финансового и социально-экономического развития // Экономическая теория. 2017. № 4. C. 60-75.

\footnotetext{
${ }^{3}$ Под финансиализацией понимается расширение роли финансовой деятельности в экономике в целом и для отдельной компании в частности.
} 
Кудрявиева Ю.В. Рынок банковских услуг: от настоящего к будущему // Финансовая аналитика: проблемы и решения. 2017. Т. 10. № 4. С. 435-448.

Кузнеиов В. А. Краудфандинг: актуальные вопросы регулирования // Деньги и кредит. 2017. № 1. С. 65-73.

Михайлов А. Ю. Ценообразование на рынке криптоактивов и взаимосвязь с фондовыми индексами // Финансы и кредит. 2018. Т. 24. № 3. С. 641-651.

Нурмухаметов Р. К., Степанов П.Д., Новикова Т. Р. Технология блокчейн: сущность, виды, использование в российской практике // Деньги и кредит. 2017. № 12. C. 101-103.

Обухов В.В., Осиповская А. В. Электронный банкинг в банковском обслуживании // Экономический журнал. 2012. № 3. С. 76-84.

Обухова E.A. ICO как современный способ финансирования высокотехнологичных проектов // ЭКО. 2018. № 3. С. 181-192.

Осадчий Н.К. Цифровая трансформация отрасли банковских услуг: анализ российской и зарубежной практики // Экономика. Бизнес. Банки. 2017. Т. 8. C. $123-129$.

Панова E.A. Краудфандинг как альтернативный инструмент финансирования малого и среднего бизнеса // Финансы и кредит. 2018. Т. 24. № 1. C. $238-250$.

Пестунов А.И. Криптовалюты и блокчейн: потенциальные применения в государстве и бизнесе // ЭКО. 2018. № 8. С. 78-92.

Савина Т.Н. Цифровая экономика как новая парадигма развития: вызовы, возможности и перспективы // Финансы и кредит. 2018. Т. 24. № 3. С. 579-590.

Трофимов Д.В. Финансовые технологии в сфере розничных платежей: тенденции развития и перспективы в ЕС и России // Вопросы экономики. 2018. № 3. С. 48-63.

Усоскин В.М., Белоусова В.Ю., Козырь И.О. Финансовое посредничество в условиях развития новых технологий // Деньги и кредит. 2017. № 5. С. 14-21.

Устюжанина E.B., Сигарев А.В., Шеин Р.А. Цифровая экономика как новая парадигма экономического развития // Экономический анализ: теория и практика. 2017. Т. 16. № 12. С. 2238-2253.

Филимонова Н.Г., Озерова М.Г., Ермакова И.Н. Развитие краудфандинга в сельском хозяйстве России // АПК: экономика, управление. 2017. № 7. C. $68-77$.

Филин С.А., Чайковская Л.А. Криптовалюта: особенности регулирования, возможности учета и налогообложения // Экономика и управление: проблемы, решения. 2018. Т. 1. № 3. С. 65-79.

Banking Beyond Banks and Money. A Guide to Banking Services in the TwentyFirst Century. Tasca, P., Aste, T., Pelizzon, L., Perony, N. (Eds.). N. Y.: Springer, 2016.

HM Treasury, EY. UK Fintech. On the cutting edge. An evaluation of the international FinTech sector, 2015.

KPMG. The Pulse of Fintech, Q12016. Global Analysis of Fintech Venture Funding.

Sigova M. V., Khon O.D. Digital banking in Russia: the mainstream of FinTech // Ученые записки Международного банковского института. 2017. № 2. С. 44-55. 


\section{Summary}

Kotliarov I.D., National Research University Higher School of Economics St. Petersburg, St. Petersburg

\section{FinTech: Nature and Models of Implementation}

The paper analyzed the nature of financial technologies (FinTech). A historical periodization of evolution of FinTech is proposed. A list of factors that led to the emergence and fast development of FinTech is given. A list of main models of coexistence of traditional and innovative models of financial services is proposed. It is demonstrated that the financial services market will be dominated by financial institutions that combine traditional and innovative models.

Financial technologies; FinTech; banks; financial services

\section{References}

Dem'yanova E.A. (2017). Kriterii otsenki riskov razvitiya kompaniy v usloviyakh vnedreniya finansovykh tekhnologiy, Finansy: teoriya i praktika [Finance: Theory and Practice]. Vol. 21. No. 4. Pp. 182-190. (In Russ.).

Kornivskaya V.O. (2017). Bitkoyn i blokcheyn skvoz' prizmu glubinnykh usloviy finansovogo i sotsial'no-ekonomicheskogo razvitiya, Ekonomicheskaya teoriya [Economic Theory]. No. 4. Pp. 60-75. (In Russ.).

Kudryavtseva Yu.V. (2017). Rynok bankovskikh uslug: ot nastoyashchego k budushchemu, Finansovaya analitika: problemy i resheniya [Financial Analytics: Problems and Solutions]. Vol. 10. No. 4. Pp. 435-448. (In Russ.).

Kuznetsov V.A. (2017). Kraudfanding: actual'nye voprosy regulirovaniya, Den'gi i kredit [Money and Credit]. No. 1. Pp. 65-73. (In Russ.).

Mikhaylov A. Yu. (2018). Tsenoobrazovanie na rynke kriptoaktivov i vzaimosviaz' s fondovymi indeksami, Finansy i kredit [Finance and Credit], Vol. 24. No. 3. Pp. 641-651. (In Russ.).

Nurmukhametov R.K., Stepanov P.D., Novikova T.R. (2017). Tekhnologiya blockcheyn: sushchnost', vidy, ispol'zovanie v rossiyskoy praktike, Den'gi i kredit [Money and Credit]. No. 12. Pp. 101-103. (In Russ.).

Obukhov V.V., Osipovskaya A. V. (2012). Elektronnyy banking v bankovskom obsluzhivanii, Ekonomicheskiy zhurnal [Economic Journal]. No. 3. Pp. 76-84. (In Russ.).

Obukhova E.A. (2018). ICO kak sovremennyy sposob finansirovaniya vysokotekhnologichnykh proyektov, EKO [ECO]. No. 3. Pp. 181-192. (In Russ.).

Osadchiy N.K. (2017). Tsifrovaya transformatsiya otrasli bankovskikh uslug: analiz rossiyskoy i zarubeshnoy praktiki, Ekonomika. Biznes. Banki [Economics. Business. Banks]. Vol. 8. Pp. 123-129. (In Russ.).

Panova E.A. (2018). Kraudfanding kak al'ternativnyy instrument finansirovaniya malogo i srednego biznesa, Finansy $i$ kredit [Finance andCcredit]. Vol. 24. No. 1. Pp. 238-250. (In Russ.).

Pestunov A.I. (2018). Kriptovalyuty i blokcheyn: potentsial'nye primeneniya v gosudarstve biznese, EKO [ECO]. No. 8. Pp. 78-92. (In Russ.).

Savina T.N. (2018). Tsifrovaya ekonomika kak novaya paradigma razvitiya: vyzovy, vozmozhnosti i perspektivy, Finansy $i$ kredit [Finance and Credit]. Vol 24. No. 3. Pp. 579-590. (In Russ.). 
Trofimov D. V. (2018). Finansovye tekhnologii v sfere roznichnykh platezhey: tendentsii razvitiya i perspektivy v ES i Rossii, Voprosy Ekonomiki [Problems of Economics]. No. 3. Pp. 48-63. (In Russ.).

Usoskin V.M., Belousova V. Yu., Kozyr' I.O. (2017). Finansovoe posrednichestvo v usloviyakh razvitiya novykh tekhnologiy, Den'gi $i$ kredit [Money and Credit]. No. 5. Pp. 14-21. (In Russ.).

Ustyuzhanina E.V., Sigarev A.V., Shein R.A. (2017). Tsifrovaya ekonomika kak novaya paradigma ekonomicheskogo razvitiya, Ekonomicheskiy analiz: teoriya i praktika [Economic Analysis: Theory and Practice]. Vol. 16. No. 12. Pp. 2238-2253.

Filimonova N.G., Ozerova M. G., Ermakova I. N. (2017). Razvitie kraudfandinga v sel'skom khozyaystve Rossii, APK: ekonomika, upravlenie [Agro-industrial Complex: Economics, Management]. No. 7. Pp. 68-77. (In Russ.).

Filin S.A., Chaykovskaya L.A. (2018). Kriptovalyuta: osobennosti regulirovaniya, vozmozhnosti ucheta i nalogooblozheniya, Ekonomika i upravlenie: problemy, resheniya [Economics and Management: Problems, Solutions], Vol. 1. No. 3. Pp. 65-79. (In Russ.).

Banking Beyond Banks and Money. A Guide to Banking Services in the TwentyFirst Century. (2016). Tasca P., Aste T., Pelizzon L., Perony N. (Eds.). N.Y.: Springer.

HM Treasury, EY. UK Fintech. (2015).On the cutting edge. An evaluation of the international FinTech sector.

KPMG. The Pulse of Fintech, Q12016. Global Analysis of Fintech Venture Funding.

Sigova M.V., Khon O.D. (2017). Digital banking in Russia: the mainstream of FinTech, Uchenye zapiski Mezhdunarodnogo bankovskogo institute [Scientific Journal of the International Banking Institute]. No. 2. Pp. 44-45. 